\title{
EXPLORING VIRTUAL REALITY TO IMPROVE ENGINEERING STUDENTS' SPATIAL ABILITIES. PILOT STUDY
}

\author{
F. Alpiste, J. Torner, M. Brigos \\ Universitat Politècnica de Catalunya. Barcelona TECH (SPAIN)
}

\begin{abstract}
A Virtual Reality pilot study is conducted to improve the spatial ability of engineering students based on solid geometry scenarios.

A total of 20 participants completed three activities $(6 \mathrm{~h})$ in an immersive virtual learning environment (IVLE), using head-mounted display (HMD) glasses.

Modeling exercises of three-dimensional geometric shapes are proposed, based on concepts of solid geometry.

The scenarios are built step by step and the students can regulate the progress between stages while observing the geometric components at the scale and in the point of view they wish.

Interaction takes place through the keyboard and visualization through an HMD headset. The transitions between different states are created by means of animations that progressively build the elements by following the instructions for the exercise.

Beyond academic results, the assessment of student improvement is based on spatial abilities tests: the Differential Aptitude Test: Spatial Relations Subset DAT-SR, Purdue Spatial Visualisation Test: Rotations PSVT:R and Mental Cutting Test MCT. Those tests are applied for evaluating different skills: mental folding, mental rotation and section by a plane. The results obtained confirm the interest in using IVLE to develop spatial abilities in engineering students. Substantial increases of $10,9 \%$ in DAT:SR, 8,8 \% in PSVT:R and 9,5\% in MCT between pre- and post-tests were found. Moreover, the students' opinion of IVLE/HMD activities is positive.
\end{abstract}

This work forms part of the investigation that the LAM-UPC, Barcelona TECH group has been conducting with the aim of enhancing the development of the spatial ability of engineering students.

In summary, a methodology is proposed developing activities in an (IVLE) with 3D modelling software applied in solid geometry, in order to promote the development of spatial abilities (SA). Spatial abilities are measured before and after the classroom activities and looking for correlations between the spatial perception tests (DAT:SR, PSVT:R and MCT) and academic results in solid geometry.

This paper describes the exploratory methodology used.

Keywords: Spatial ability (SA), virtual reality (VR), assessment of student learning, teaching engineering, head-mounted display (HMD), solid geometry.

\section{INTRODUCTION}

The evaluation of students' skills and the didactic methodologies for improving them are constant concerns of University Engineering Departments. In particular, the LAM-UPC, Barcelona TECH research group pursues a research line on spatial ability and the teaching of "Graphic Expression and Computer-Aided design" [1] .

The importance of spatial ability (SA) in engineering design processes has been analyzed in many studies in which methodologies have been proposed for improving SA competence in students [2-13]. In general, all these studies use systems for measuring SA as well as analyzing contextual variables, competence and academic results to look for correlations that underpin methodologies for the development of SA.

The concept of SA is split into multiple sub-factors and it is difficult to find a definition that may be unanimously accepted by the whole scientific community. However, we find two basic components of SA competence that are commonly accepted: 
- Spatial vision: the ability to manipulate an object in an imaginary 3D space in order to create representations of the object from different points of view.

- Spatial Orientation: the ability to navigate through our surroundings and predict the movement and position of objects.

At present, various tests exist that enable us to focus on the different components of this skill [3]. The most commonly employed tests for measuring spatial vision are as follows:

- DAT-SR, Differential Aptitude Test-Spatial Relations Subset Mental folding. This consists in relating a three-dimensional shapes with the image of their development in 2D [14]..

- MRT, Mental Rotation Test. Mental rotation. Here it is necessary to identify 3D shapes as rotated representations of an object [15].

- PSVT:R, Purdue Spatial Visualization Test. Mental Rotation. Two images of the same solid are shown both before and after rotation. This consists in applying the same rotation to another given solid and selecting the resulting image [16-17].

- MCT. Mental Cutting Test. Given a figure intersected by a plane, it is necessary to determine the result of the section [18]. Table 1 shows test item examples.

Table 1: Test Item Examples

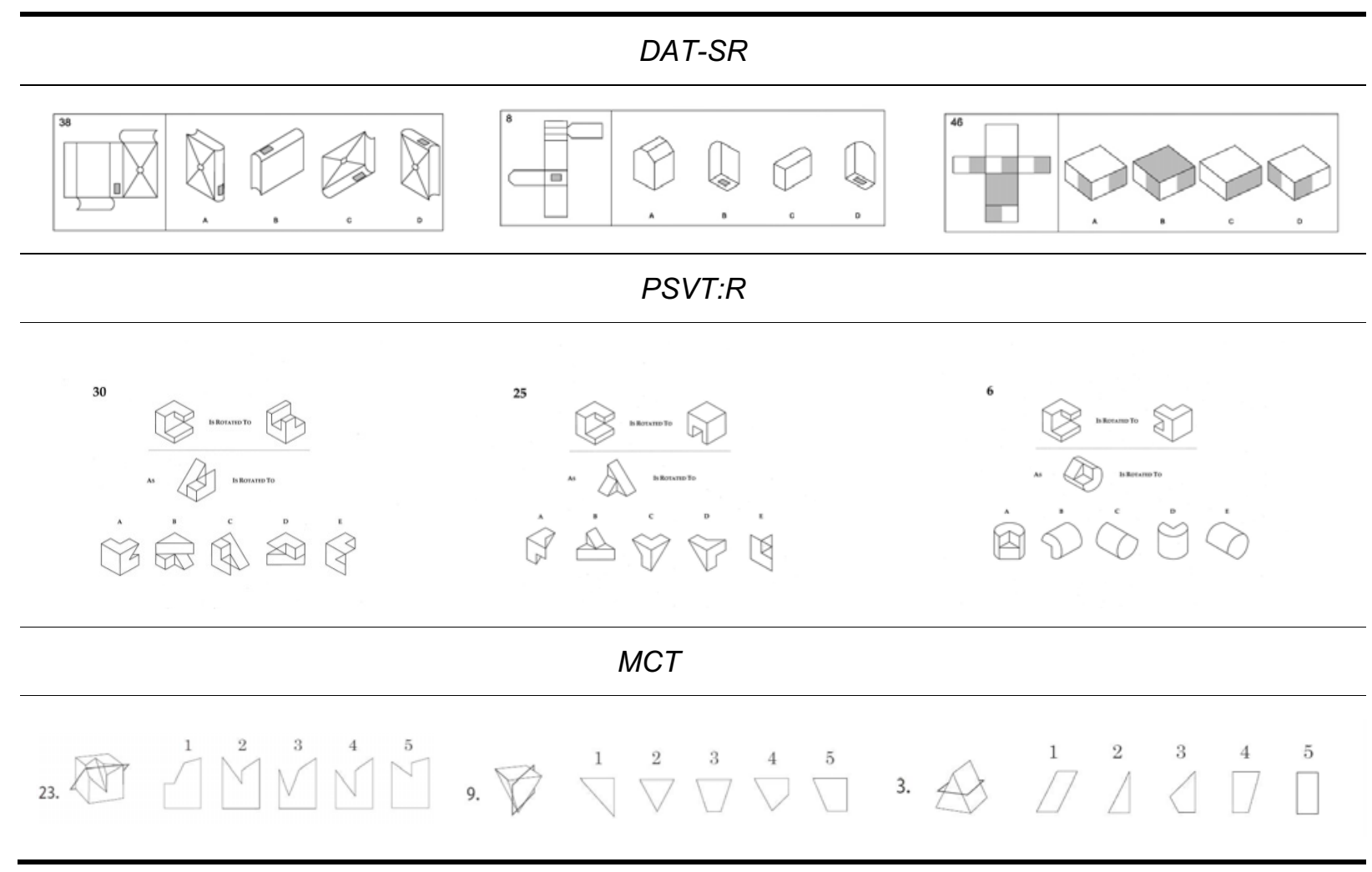

\subsection{Virtual reality applied in spatial Ability}

There are many precedents for the use of VR in learning and, in particular, in the improvement of spatial skills in engineering design [19],[20].

VR uses hardware and software to create a sensation of navigation, manipulation and immersion [21]. VR can be divided into three categories: text-based, desktop and immersive VR.

Text-based networked VR is based in text communication. This type of VR has commonly been used in education and training [22].

Desktop VR is an 3D images environment but without being considered immersive. [23]. The applications developed here are immersive VR. It consists of a combination of hardware, software and interaction that enable the user to be immersed in a computer-generated three-dimensional world [24]. 
VR can provide an effective resource to improve some skills. For instance, it is applied in simulators to train sensory motor skills [25]. VR is widely used in rehabilitation and surgical training [26].

Some interesting applications are those that enable students to visualize abstract concepts, such as chemical bonds and other chemistry-related contents [27],[28] or those that enable them to interact with objects that are otherwise unavailable due to distance, time or safety constraints $[29],[30],[31],[32]$. Other field of application is the training in maintenance and industrial manufacturing [33],[34],[35].

There are different ways in which VR technology can aid learning. W. Winn [36] and V.S. Pandelidis [37] identified the main contributions of VR as interaction or participation, immersion, and motivation.

Finally, some researchers are focused to improve spatial abilities in first engineering courses using virtual technologies: augmented reality and virtual reality. Many interesting VR contributions are related to computer graphics learning environments [38], immersive 3D VR HDM in spatial volumes [39], engineering graphics [40],[41] and virtual technologies to develop visual-spatial memory [42], [43], rotation capacity [44], orientation [45], open environments [46] ,virtual navigation [47], and visualspatial ability by and large [48].

In summary, VR is used widely in learning processes. Moreover, VR boosted significant improvements in SA training.

\subsection{Head-mounted display (HMD)}

HMD devices currently reproduce two images with a slightly different focus on a monitor similar to that of a smartphone. The results cause a high level of immersion, while the movements of the head change the point of view of the receiver, enabling us to simulate movement in the scenario by means of a keyboard or joystick.

Technical characteristics of Oculus Rift:

Display
Resolution
Refresh Rate
Persistence
Viewing Optics
Internal Tracking
Sensors
Update Rate
Positional Tracking
Sensors
Update Rate

$960 \times 1080$ per eye

$75 \mathrm{~Hz}, 72 \mathrm{~Hz}, 60 \mathrm{~Hz}$

$2 \mathrm{~ms}, 3 \mathrm{~ms}$, full

$100^{\circ}$ Field of View (nominal)

Gyroscope, Accelerometer, Magnetometer

$1000 \mathrm{~Hz}$

Near Infrared CMOS Sensor

$60 \mathrm{~Hz}$

\subsection{Development software for Oculus Rift}

The best resolution was obtained using Cinema4D in *.fbx format and importing it into the Unity game engine, in which the user movement and interaction commands had been programmed. The animation was created using Unity's Legacy tool.

\section{METHODOLOGY}

In a previous study [1], participating 812 freshman students of Industrial Engineering at the Universitat Politècnica de Catalunya, Barcelona TECH, we obtained the correlation between the SA values and the academic results from the thematic blocks (3D modeling with $2 \mathrm{D}$ drawings $(2 \mathrm{Oh})$ and solid geometry (15h).

There was a clear relationship between the initial DAT-PRE and the test that assesses students' knowledge of solid geometry. Therefore, we propose to harness the potential of these activities with solid geometry in order to maximize the development of SA. It is for this reason that VR exercises in spatial geometry were proposed. 
The VR scenarios are built step by step and the students can regulate the progress between stages while observing the geometric components at the scale and in the point of view they wish. The activities consisted of creating applications to model three-dimensional geometric shapes, introducing the concepts of geometry progressively. Students could interact freely with each scenario and move forward and backward through the sequence of steps. Interaction takes place through the keyboard and visualization through an HMD headset.

The transitions between different states are created by means of animations that progressively build the elements by following the instructions for the exercise.

The notation and iconography used in the reference software (Solid Works) has been included to aid comprehension (Figure 1).
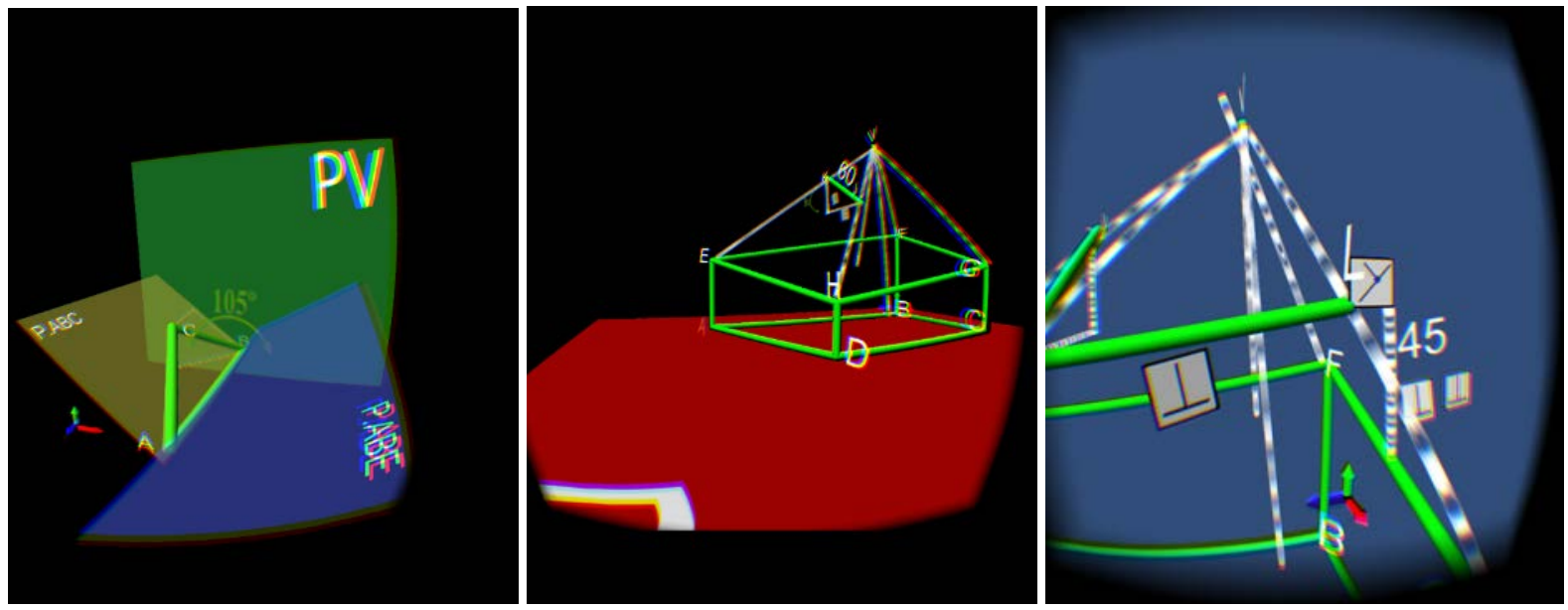

Figure 1. Screenshot from exercises. Annotations and symbols

The methodology can be summarized in the following steps:

1. Students take the DAT:SR, PSVT:R and MCT prior to the activities (pre). They also take the survey on controlled variables that can affect SA $(1.15 \mathrm{~h})$.

2. The students individually complete the exercises with the 3D modeling software Solid Works $(10 \mathrm{~h})$.

3. The IVLE activities consist of the guided reading by the professor of the completed exercise. The professor addresses the concepts of solid geometry used in each step. The students have a few minutes to view the animation showing the construction of the geometric shape, and once the representation is finished, they can move freely throughout the scenario, using the keyboard options $(6 \mathrm{~h})$. Figure 3 .

4. Students take the (DAT:SR, PSVT:R and MCT after the IVLE activities (pos). At the end, the groups that have worked in the IVLE also take the satisfaction survey $(1.15 \mathrm{~h})$.

5. All the students are assessed on their knowledge of the solid geometry contents by means of a test and 3D modeling exercises similar to those done in class and those described in the IVRL.

6. Finally, the analysis of the spatial abilities test data, controlled variable surveys, satisfaction surveys and the academic results obtained in the solid geometry module enable us to examine the correlations and the strongest determining factors in order to obtain good academic results and propose IVLE activities to improve the levels of spatial ability obtained on the tests. 

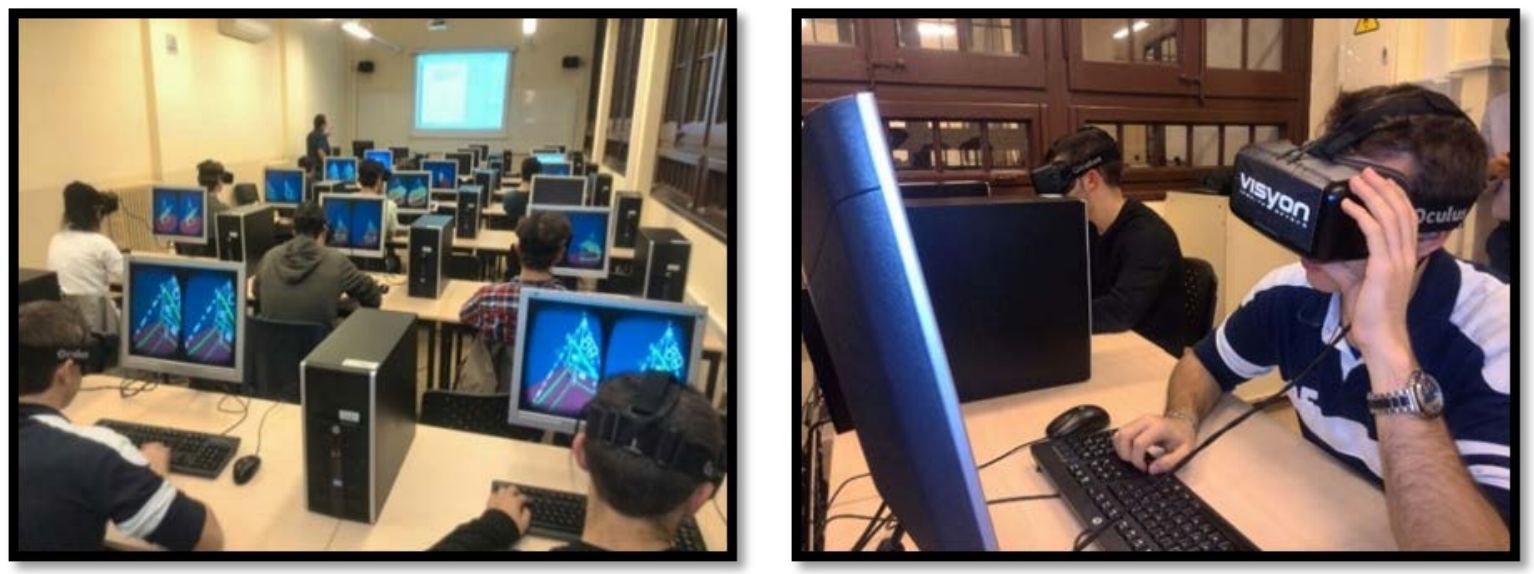

Figure 3. IVLE sessions. HMD

\section{RESULTS}

\subsection{Improvement of spatial skills}

Table 2 shows the means and standard deviations of the tests performed. The course start (pre), the course end (pos) and the improvements obtained (post-pre). The pre- and post-tests are useful for demonstrating progress in learning and for perfecting teaching approaches, thereby addressing the identified erroneous concepts and applying new and/or different didactic strategies [10],[49],[50].

The maximum scores are different in each test: DAT-SR $=60$, PSVT: $R=30$ and $M C T=25$. To be able to compare the results, in this case scores are shown in percentages of hits over 100. The scores improved an average of $10.9 \%$ on the total score in DAT-SR, $8.8 \%$ in PSVT: R, and $9.5 \%$ in MCT. The significance of the gains was checked with the $T$ test for related samples and Wilcoxon $(p<0.01)$.

Table 2. Average scores (\%) Pre, Pos, Gain and Standard deviation (SD) in DAT-SR, PSVT-R and MCT.

\begin{tabular}{|ccc|ccc|cccc|}
\hline \multicolumn{8}{c|}{ Average scores (\%) (SD) } \\
\hline \multicolumn{3}{|c|}{ DAT-SR } & \multicolumn{3}{c|}{ PSVT-R } & \multicolumn{3}{c|}{ MCT } \\
\hline Pre & Pos & Gain & Pre & Pos & Gain & Pre & Pos & Gain \\
\hline 73,1 & 83,0 & 10,9 & 75,1 & 84,8 & 8,8 & 61,0 & 67,6 & 9,5 \\
$(15,9)$ & $(13,6)$ & $(10,0)$ & $(16,0)$ & $(11,1)$ & $(11,1)$ & $(17,8)$ & $(19,4)$ & $(11,6)$ \\
\hline
\end{tabular}

$67 \%$ of students improved in MCT. In the DAT test, the percentage was higher (87\%). However, if the number of students who improved more than a $10 \%$ score is considered,

the percentage is very similar in DAT and MCT (44.9 and $43.9 \%$ respectively) and is reduced in PSVT: $\mathrm{R}$ at $29.6 \%$.

The improvements after studying Graphic Expression are very similar to those described by Torner (2009) [1] and Contero et al. (2006) [51] in the DAT-SR test; similar to those of Mataix (2014) [52], superior to Connolly (2009) [53] in PSVT: R and similar to Leopold et al. (2001) [2] in MCT.

\subsection{Correlations between marks and SA tests}

One of the objectives of this work is to determine if the spatial skills tests, DAT-SR, PSVT: R and MCT can predict the academic result in the different thematic blocks of the Graphic Expression subject. The results allow detecting students with poor spatial skills and allow proposing didactic activities to improve them.

Students with DAT-SR pre-test scores fewer than 40, PSVT-Pre under 20 or MCT-Pre under 16 were provided with complementary leveling activities. 
The subject Graphic Expression is imparted with the 3D modeling software "Solid Works" and includes the following thematic blocks: 3D modeling with 2D drawings (20h) and Solid Geometry (15h). The two modules are evaluated with the DAO 1 and DAO 2 tests.

The DAT-SR pre-test is the best one correlated (Pearson) to the DAO 1 and 3D modeling with 2D drawings $(r=0.36, p<0.001)$. If only 3D modeling is evaluated (without $2 \mathrm{D}$ drawings), DAT-SR and MCT have very similar correlations: DAT-SR-Pre $(r=0.43, p<0.001)$ and MCT-Pre $(r=0.41, p$ $<0.001)$. In Solid Geometry (DAO 2, test), the highest correlation is obtained with MCT-Pre $(r=0.36, p$ $<0.001)$.

The SA test best related to the final grade of the subject is MCT-Pos $(r=0.46, p<0.001)$. It suggests that skills required in Graphic Expression are more related to the ability to mentally cut a solid by a plane than with mental folding or mental rotation.

Positive correlations of the academic results with MCT have also been observed in other studies [50],[2],[54].

\subsection{Satisfaction survey results}

The students' opinion with regard to the proposed activities are positive. They have the perception that the system is easy to use, enable them to better understand the contents presented and they consider it to be useful. Therefore, in agreement with the findings of Lau, K. et al. [55], the use of VR motivates students during their learning process.

Table.3. Satisfaction survey results

\begin{tabular}{|l|}
\hline The immersion system is easy to use \\
\hline Strongly disagree $0 \%$ \\
\hline Disagree $0 \%$ \\
\hline Neither agree nor disagree $26 \%$ \\
\hline Agree $63 \%$ \\
\hline Strongly agree $11 \%$ \\
\hline \\
\hline The content provided is easy to understand \\
\hline Strongly disagree $0 \%$ \\
\hline Disagree $11 \%$ \\
\hline Neither agree nor disagree $58 \%$ \\
\hline Agree $32 \%$ \\
\hline Strongly agree $11 \%$ \\
\hline \\
\hline Immersion system provides useful content \\
\hline Strongly disagree $0 \%$ \\
\hline Disagree $0 \%$ \\
\hline Neither agree nor disagree $16 \%$ \\
\hline Agree $47 \%$ \\
\hline Strongly agree $37 \%$ \\
\hline
\end{tabular}

\section{CONCLUSIONS}

After including VR, Interesting results were obtained: substantial increases of $10,9 \%$ in DAT, $8,8 \%$ in PSVT:R and 9,5\% in MCT pre and post-tests. We obtained the correlation between the SA values and the academic results from the thematic blocks (3D modeling with 2D drawings (2Oh) and Solid Geometry (15h). The greatest correlation occurred between the DAT pre-test and the MCT pre-test and the assessment of solid geometry. MCT seems to be a good indicator of success in the module since it shows the highest amount of correlations.

The students' opinion of IVLE/HMD activities is positive and its use motivates students during their learning process.

Future works could introduce: 3D tests, Geometric immersive 3D graphic design software and Augmented Reality (AR). 
3D tests could be used. Currently the tests are presented in forms (Google Drive template) incorporating 2D images, taken from the test paper [56]. Some cases already exist in which immersive 3D tests have been applied, such as the Virtual Reality Spatial Rotation (VRSR) system (Rizzo, A. A. et al., 1998) [57], which make it possible to administer the Mental Rotation Test (MRT) directly in 3D, providing improvements over the administration of the paper-and-pencil MRT.

Geometric immersive 3D graphic design software could also be added. Dünser, A. et al. (2006) [58] use drawing software that makes it possible to generate 3D models, move around them and modify them in real time. Visualization relies on HMD glasses.

Augmented reality (AR) uses a combination of the user's physical environment and real-time interactive computer representations. One proposal for future work could be to incorporate geometry topics that combine both real and synthetic images. This could be extremely useful for design validation in engineering design courses [59-63].

Within the plans for continuing this study is the incorporation of some of these tools in the near future.

\section{REFERENCES}

[1] J. Torner, F. Alpiste, M. Brigos, "Spatial Ability in Computer-Aided Design Courses," Comput. Aided Des Appl. Taylor \& Francis, vol. 20, pp. 1-9. 2014. Retrieved from: http://dx.doi.org/10.1080/16864360.2014.949572

[2] C. Leopold, A. Renata, S. Sorby, "International Experiences in Developing the Spatial Visualization Abilities of Engineering Students," J Geom Graph. 2001. Retrieved from: http://www.uni-kl.de/AG-Leopold/dg/mediadata/fachgebiet/personen/aufsatz_vol51.ps

[3] C. Melgosa Pedrosa, B. Ramos Barbero, M.E. Baños García. "Interactive learning management system to develop spatial visualization abilities." Comput Appl Eng Educ. 2013. Retrieved from: http://onlinelibrary.wiley.com/doi/10.1002/cae.21590/abstract

[4] S. Strong, R. Smith, "Spatial Visualization: Fundamentals and Trends in Engineering Graphics". $J$ Ind. Technol. 2001. Retrieved from:

http://www.researchgate.net/publication/242042592_Spatial_Visualization_Fundamentals_and_ Trends_in_Engineering_Graphics

[5] N.W.Hartman, G.R. Bertoline, "Spatial Abilities and Virtual Technologies: Examining the Computer Graphics Learning Environment". Ninth International Conference on Information Visualisation (IV'05) IEEE. pp. 992-7. 2005. Retrieved from:

http://ieeexplore.ieee.org/lpdocs/epic03/wrapper.htm?arnumber=1509193

[6] S. Sorby S, B. Baartmans, "The Development and Assessment of a Course for Enhancing the 3D Spatial Visualization Skills of First Year Engineering Students," J Eng Educ. 2000. Retrieved from: http://onlinelibrary.wiley.com/doi/10.1002/j.21689830.2000.tb00529.x/abstract

[7] S.Sorby, "Educational Research in Developing 3D Spatial Skills for Engineering Students," Int J Sci Educ. Routledge, vol.31, no 3, pp. 459-80. 2009. Retrieved from: http://dx.doi.org/10.1080/09500690802595839

[8] S. Sorby, S. Cubero, N. Pasha-zaidi, H. Karki H. "Spatial skills of engineering students in the United Arab Emirates," World Congress on Engineering Education. 2014

[9] J.L. Saorín-Pérez, R.E. Navarro-Trujillo, N. Martín-Dorta, J. Martín-Gutiérrez, M. ConteroGonzalez, "La capacidad espacial y su relación con la ingeniería," Dyna. Federación de Asociaciones nacional de ingenieros industriales de España, vol. 84, no. 9. Pp. 721-32, 2009.

[10] H.M. Steinhauer, "The transferability of the PSVT: R and the MCT for Measuring and Predicting Student 3D CAD Modelling Abilities," Research in Engineering Education Symposium 2011, REES. pp. 874-82. 2011. Retrieved from: http://www.scopus.com/inward/record.url?eid=2-s2.084883091745\&partnerID=tZOtx3y1

[11] H.M. Steinhauer, "Correlation between a student's performance on the mental cutting test and their 3d parametric modeling ability," Engineering Design Graphics Journal. pp. 44-8. 2012. Retrieved from: http://www.scopus.com/inward/record.url?eid=2-s2.084874258740\&partnerID=tZOtx3y1 
[12] J. Harris J, K. Hirsh-Pasek K, N.S. Newcombe, "Understanding spatial transformations: similarities and differences between mental rotation and mental folding," Cogn Process. vol.14, no 2, pp.105-15. 2013. Retrieved from: http://www.ncbi.nlm.nih.gov/pubmed/23397105

[13] M. Hegarty, D.R. Montello, A.E.Richardson, T. Ishikawa T, K. Lovelace, "Spatial abilities at different scales: Individual differences in aptitude-test performance and spatial-layout learning," Intelligence, vol. 34, pp. 51-76. 2006.

[14] G.K. Bennett, H.G. Seashore, A. Wesman, "Differential aptitude tests, Forms S and T". Psychol Corp New York. Psychological Corp. 1973.

[15] S.G. Vandenberg, A.R. Kuse, "Mental Rotations : a Group Test of Three-Dimensional Spatial Visualization," Percept Mot Skills, vol. 47, pp.599-604. 1978. Retrieved from: http://ci.nii.ac.jp/naid/10004192955/en/

[16] R. Guay, "Purdue spatial visualization test: Rotations," West Lafayette, IN: Purdue Research Foundation.1977.

[17] S.Y. Yoon, "Revised Purdue Spatial Visualization Test: Visualization of Rotations (Revised PSVT:R)," Psychometric Instrument. 2011.

[18] CEEB. CEEB Special Aptitude Test in Spatial Relations (MCT) Developed by the College Entrance Examination Board, USA. 1939.

[19] A. G. Abulrub, A. Attridge and M. A. Williams, "Virtual Reality in Engineering Education: The Future of Creative Learning," International Conference IEEE EDUCON. 2011.

[20] D. Vergara, M. P. Rubio and M. Lorenzo "On the Design of Virtual Reality Learning Environments in Engineering," Multimodal Technologies and Interact. vol.1, no.11, doi:10.3390/mti1020011. 2017.

[21] S. Helsel, "Virtual Reality and Education," Educational Technology, vol.32, no.5, pp. 38-42. 1992.

[22] J. Psotka, "Immersive Tutoring Systems: Virtual Reality and Education and Training," Instructional Science 23, pp. 405-431, 1995.

[23] D. Waller and J.A. Miller, "Desktop virtual environment trainer provides superior retention of a spatial assembly skill," ACM SIGCHI '98, Los Angeles, CA. 1998.

[24] C. E. Loeffler and T. Anderson (eds.), "The Virtual Reality Casebook," New York: Van Nostrand Reinhold. 1994.

[25] F. Amin Nur Yunus, J. Abd Baser, S. Hadi Masran, N. Razali, and B. Rahi," Virtual Reality Simulator Developed Welding Technology Skills," Journal of Modern Education Review, ISSN 2155-7993, USA, vol. 1, no. 1, pp. 57-62. 2011.

[26] M. Nagendran, K.S. Gurusamy, R. Aggarwal, M. Loizidou and B.R. Davidson, "Virtual reality training for surgical trainees in laparoscopic surgery Intervention review," The Cochrane Collaboration. John Wiley \& Sons, Ltd. DOI: 10.1002/14651858.CD006575.pub3. 2013.

[27] D. Carlisle, J.F. Tyson, and M. Nieswandt, "Fostering spatial skill acquisition by general chemistry students," Chemistry Education Research and Practice. 2015.

[28] Z. Merchant, E.T. Goetz, W. Keeney-Kennicutt, L. Cifuentes, O. Kwok and T.J. Davis, "Exploring 3-D virtual reality technology for spatial ability and chemistry achievement," Journal of Computer Assisted Learning, vol. 29, pp. 579-590, John Wiley \& Sons Ltd. 2013.

[29] G. Javidi, "Virtual reality and education, Master Thesis," University of South Florida.1999.

[30] M. Harle and M. Towns, "A review of spatial ability literature, its connection to chemistry, and implications for instruction," Journal of Chemical Education, vol. 88, pp. 351-360. DOI: 10.1021/ed900003n. 2011.

[31] J. García, J. Entrialgo, "Using computer virtualization and software tools to implement a low cost laboratory for the teaching of storage area networks," Comput. Appl. Eng. Educ., vol. 23, pp. 715-723. 2015.

[32] D. Vergara, M.P. Rubio, F. Prieto, M. Lorenzo, "Enhancing the teaching/learning of materials mechanical characterization by using virtual reality," J. Mater. Educ., vol. 38, pp. 63-74. 2016. 
[33] N. Gavish, T. Gutiérrez, S. Webel, J. Rodríguez, M. Peveri, U. Bockholt and F. Tecchia, "Evaluating virtual reality and augmented reality training for industrial maintenance and assembly tasks," Interactive Learning Environments (ahead-of-print), pp. 1-21. DOI: 10.1080/10494820.2013.815221. 2013.

[34] L.P. Berg, J.M. Vance, "Industry use of virtual reality in product design and manufacturing: A survey," Virtual Real., pp. 1-17, 2016.

[35] S. Choi, K. Jung, S.D. Noh, "Virtual reality applications in manufacturing industries: Past research, present findings, and future directions," Concurr. Eng. Res. Appl., vol. 23, pp. 40-63. 2015.

[36] W. Winn, H. Hoffman, A. Hollander, K. Osberg, H. Rose and P. Char, "The Effect of Student Construction of Virtual Environments on the Performance of High- and Low-Ability Students," Human Interface Technology Laboratory. 1997.

[37] V.S. Pantelidis, S. Veronica, "Reasons to Use Virtual Reality in Education and Training Courses and a Model to Determine When to Use Virtual Reality," Themes In Science and Technology Education. Special Issue, pp. 59-70. Klidarithmos Computer Books. 2010.

[38] C.L. Miller and G.R: Bertoline, "Spatial Abilities and Virtual Technologies: Examining the Computer Graphics Learning Environment, iv," pp. 992-997, Ninth International Conference on Information Visualisation (IV '05). 2005.

[39] M.A. Schnabel and T. Kvan, "Spatial understanding in immersive virtual environments. International Journal of Architectural Computing, vol. 1, no. 4, pp. 435-448. 2003.

[40] T. R. Thornton, A.C. Clark \& M. Lammi, "Understanding how learner outcomes could be affected through the implementation of augmented reality in an introductory engineering graphics course," North Carolina State University. 2014.

[41] S. Tumkor, E. Aziz, S. Esche \& C. Chassapis, C. "Integration of augmented reality into the CAD process," In Proceedings of the ASEE Annual Conference \& Exposition, Atlanta, GA, USA. 2013.

[42] C. Oman, W. L. Shebilske, J. T. Richards, T. C. Tubré, A. C. Beall, and A. Natapoff, "Three Dimensional Spatial Memory and Learning in Real and Virtual Environments," Spatial Cognition and Computation, no. 2, pp. 355-372, 2002.

[43] C. Lin, C. Chen \& Y.Lou, "Developing spatial orientation and spatial memory with a treasure hunting game," Journal of Educational Technology \& Society, vol. 17, no. 3, pp.79-92. 2014.

[44] J.W. Regian, W.L. Shebilske \& J.M. Monk, "Virtual reality: an instructional medium for visualspatial tasks. Journal of Communication, vol. 42, no. 4, pp. 136-149. 1992.

[45] J. Martin Gutierrez, M. Garcia Dominguez, \& C. Roca Gonzalez, "Using 3D virtual technologies to train spatial skills in engineering," International Journal of Engineering Education, vol. 31, no. 1, pp. 323-334. 2015.

[46] M. Hegarty and D.A. Waller, "Individual differences in spatial abilities. The Cambridge Handbook of Visuospatial Thinking," Cambridge University Press, pp. 561. 2005. Retrieved from: https://books.google.com/books?id=m91B8zm_1qgC\&pgis=1

[47] R. Darken \& S.R. Goerger, "The transfer of strategies from virtual to real environments: An explanation for performance differences?," Simulation Series, vol. 31, pp. 159-164. 1999.

[48] C. Roca-González, J. Martin-Gutierrez, M. García-Domínguez, M.C. Mato Carrodeguas. "Virtual Technologies to Develop Visual-Spatial Ability in Engineering Students". EURASIA Journal of Mathematics Science and Technology Education ISSN 1305-8215 (print), vol. 13, no. 2, pp. 441-468. DOI 10.12973/ eurasia.2017.00625ª 2017.

[49] J. Gluck, S. Fitting, "Spatial Strategy Selection: Interesting Incremental Information. Int J Test [Internet]. Lawrence Erlbaum Associates, Inc., vol. 3, no. 3, pp. 293-308. 2003. Retrieved from: http://www.tandfonline.com/doi/abs/10.1207/S15327574IJT0303_7\#.VR_TePmsU4g

[50] G: Adanez, A. Velasco, "Predicting Academic Success of Engineering Students in Technical Drawing from Visualization Test Scores," Journal for Geometry and Graphics. 2002.

[51] M. Contero, F. Naya, P. Company, J.L. Saorin, J. Conesa, et al., "Improving Visualization Skills 
in Engineering Education. IEEE Computer Graphics and Applications, vol. 25, no. 5, pp. 24-31. 2005.

[52] J. Mataix Sanjuán, C. León Robles,.\& F.D.P Montes Tubío, "Las habilidades espaciales de los estudiantes de las nuevas titulaciones técnicas. Estudio en la Universidad de Granada," EGA. Revista de expresión gráfica arquitectónica, vol. 19, no. 24, pp.264. 2014.

[53] P.E. Connolly, "Spatial Ability Improvement and Curriculum Content," $63^{\text {rd }}$ Annual ASEE/EDGD Mid-Year Conference Proceedings, Berkeley, California -pp.1-5. January 4-7, 2009.

[54] T.J. Branoff and N. Carolina, "Relationship Between Students ' Spatial Visualization Ability and their Ability to Create 3D Constraint-Based Models from Various Types of Drawings Relationship Between Students ' Spatial Visualization," 121st ASEE Annual Conference \& Exposition. 2014

[55] K. W. Lau, and P. Y. Lee, "The use of virtual reality for creating unusual environmental stimulation to motivate students to explore creative ideas," Interactive Learning Environments (ahead-of-print), pp.1-16. DOI: 10.1080/10494820.2012.745426. 2012.

[56] A. Villa, "Desarrollo y evaluación de las habilidades espaciales de los estudiantes de ingeniería. actividades y estrategias de resolución de tareas espaciales," PHD Thesis. Universitat Politècnica de Catalunya. (UPC), Barcelona TECH. 2015.

[57] A. A. Rizzo, J. G. Buckwalter, U. Neumann, C. Kesselman, M. Thiebaux, P. Larson, and A. Van Rooyen, The Virtual Reality Mental Rotation Spatial Skills Project. CyberPsychology and Behavior, vol.1, no.2, pp.113-120. 1998.

[58] A. Dünser, H. Kaufmann, K. Steinbügl, and J. Glück, Virtual and Augmented Reality as Spatial Ability Training Tools. 7th ACM SIGCHI New Zealand chapter's international conference on Computer-Human Interaction, pp.125-132, 2006.

[59] J. Wither, Y. T. Tsai, and R. Azuma, Indirect augmented reality. Computers \& Graphics, vol. 35, no 4, pp. 810-822, 2011.

[60] K. Lee, "Augmented reality in education and training," TechTrends, vol. 56, no 2, pp.13-21, 2012.

[61] S.K. Ong \& Y. Shen, "A mixed reality environment for collaborative product design and development," CIRP Annals-Manufacturing Technology, vol. 58, no. 1, pp.139-142. 2009.

[62] S. Martin, G. Diaz, E. Sancristobal, R. Gil, M. Castro \& J. Peire, "New technology trends in education: Seven years of forecasts and convergence," Computers \& Education, vol. 57, no 3, pp.1893-1906. 2011.

[63] H. K. Wu, S. W. Y. Lee, H. Y. Chang, and J. C. Liang, Current status, opportunities and challenges of augmented reality in education. Computers \& Education, 62, 41-49, 2013. 